\title{
Informal Employment and Pension and Healthcare Coverage by Social Insurance in Latin America
}

\author{
Carmelo Mesa-Lago
}

\begin{abstract}
1 Pensions and healthcare systems and their coverage in Latin America

This article describes Latin America's social insurance systems for pension and healthcare in the context of the region's shift in labour with decreasing formal employment and expanding informality. The analysis demonstrates that social insurance coverage (on pensions and healthcare) is higher where informality is lower and vice versa; identifies key explanatory factors for low and unequal coverage; and suggests policy recommendations for expanding coverage. By way of introduction, this section briefly explains key features of the pension and healthcare systems and their coverage in the 20 countries of Latin America (based on Mesa-Lago 2008a).
\end{abstract}

All countries have social insurance pensions for oldage, disability and survivors. Structural reforms in ten countries (Argentina, Bolivia, Chile, Colombia, Costa Rica, Dominican Republic, El Salvador, Mexico, Peru and Uruguay) shifted from the traditional defined benefit, pay-as-you-go and public administration ('public systems'), to defined contribution, fullyfunded individual accounts and private administration ('private systems'), albeit with diverse models and degrees of privatisation. The other ten countries maintain the traditional public systems and several have implemented non-structural ('parametric') reforms to strengthen them financially (Brazil, Cuba, Ecuador, Guatemala, Haiti, Honduras, Nicaragua, Panama, Paraguay and Venezuela). ${ }^{1}$

Pension coverage of the labour force by social insurance averaged 31 per cent in Latin America in 2004; in the least developed countries coverage ranged from 9 per cent to 19 per cent. Coverage in private systems was 26 per cent, compared with 39 per cent in public systems (based on surveys averages were 36 per cent and 41 per cent, respectively). Coverage fell in all ten structurally reformed private systems and the average declined from 38 per cent before the reform to 26 per cent in 2004.

Most countries in the region have three health sectors:

- Public, which legally should protect the uninsured population (the majority in 12 countries) but in practice seldom accomplish that task, and it is extremely difficult to estimate the population with access

- Social insurance sickness and maternity benefits, comprising a principal programme and often separate schemes for special labour groups, covering 41 per cent of the total population but ranging from 8 per cent to 88 per cent; this is the main provider in eight countries

- Private, the smallest sector but expanding, which covers 11.5 per cent of the population ranging from 1 per cent to 25 per cent in various countries.

Brazil and Cuba have a public system and no social insurance; the former also has a sizeable private sector that is banned in the latter; in Haiti social insurance is incipient. Healthcare reforms began in Chile in 1981 and have been implemented in virtually all countries, albeit with different scope, depth and speed; most reforms have pursued an expansion of the private sector. Health coverage of the total population by social insurance averaged 41 per cent in 2004, a decline from 52 per cent in 1990; in the least developed countries coverage ranged from 7 per cent to 17 per cent; in 75 per cent of countries between the reform and 2004 coverage either stagnated or declined. 
Table 1 Importance of informal labour in Latin America, circa 2005 (\%)

\begin{tabular}{|c|c|c|c|}
\hline $\begin{array}{l}\text { Country groups by } \\
\text { informal labour } \\
\text { importance }\end{array}$ & $\begin{array}{l}\text { Informal/urban } \\
\text { employed labour force }\end{array}$ & $\begin{array}{l}\text { Self-employed/urban } \\
\text { employed labour force }\end{array}$ & $\begin{array}{l}\text { Self-employed and unpaid } \\
\text { family/rural labour force }\end{array}$ \\
\hline Low (average) & 36.5 & 18.7 & 43.3 \\
\hline Chile & 28.5 & 15.0 & 32.0 \\
\hline Costa Rica & 32.4 & 16.1 & 24.3 \\
\hline Argentina & 37.1 & 16.7 & n.a. \\
\hline Mexico & 38.8 & 18.9 & 39.1 \\
\hline Panama & 37.0 & 21.5 & 58.7 \\
\hline Uruguay & 41.2 & 20.3 & n.a. \\
\hline Brazil & 40.5 & 22.6 & 62.5 \\
\hline Medium (average) & 46.2 & 34.8 & 49.6 \\
\hline El Salvador & 49.6 & 32.4 & 40.5 \\
\hline Dominican Rep. & 45.3 & 34.1 & 57.2 \\
\hline Colombia & 42.6 & 37.6 & 56.0 \\
\hline Venezuela & 47.4 & 35.2 & 44.9 \\
\hline High (average) & 56.3 & 36.3 & 66.5 \\
\hline Ecuador & 51.9 & 31.6 & 56.8 \\
\hline Guatemala & 51.6 & 34.5 & 58.4 \\
\hline Honduras & 54.2 & 36.7 & 63.0 \\
\hline Nicaragua & 55.5 & 35.4 & 57.2 \\
\hline Paraguay & 55.7 & 29.5 & 70.4 \\
\hline Peru & 60.0 & 42.0 & 80.5 \\
\hline Bolivia & 65.4 & 44.1 & 79.2 \\
\hline Regional average & 46.4 & 29.1 & 55.0 \\
\hline
\end{tabular}

*No data available for Cuba and Haiti. †Sum of self-employed, unpaid family workers, domestic servants and employees in microenterprises (less than five employees). $\neq$ Percentage of the urban labour force occupied with low productivity that is unskilled self-employed. §Percentage of the rural labour force that is selfemployed or unpaid family worker.

Author's estimates based on ECLAC (2006b); and non-weighted averages.

\section{Transformation of the labour market and legal}

\section{protection}

As in most of the world, social insurance in Latin America was designed for the formal sector of the economy, essentially urban, with fairly stable employment and income. Coverage was higher in those countries with the largest formal sector and the smallest informal sector that is normally uninsured. During the economic crisis of the 1980s the formal sector contracted while the informal sector expanded - a trend that basically continues and has adversely affected coverage. This situation has been aggravated by the 'flexibilisation' of the labour market introduced by neoliberal reforms, which transformed jobs fully protected by labour and social security legislation into jobs without contract, part-time or subcontracted, all devoid of social protection (Tokman 2007).
The definition and scope of the informal sector has been the subject of discussion for decades and for a long time was restricted to the urban sector. Recently, an international agreement was reached to expand its scope to the rural sector, new more concrete definitions developed, and an attempt is underway to elaborate more reliable and comparable statistics (Chen, in this IDS Bulletin). In Latin America, data on the informal sector was based on the old concept of informality and limited to the urban sector. This article elaborates preliminary new statistics combining informality in the urban and rural sectors (unfortunately data from ECLAC are based on percentages that do not allow merging of the sectors so estimates are separate). The urban informal sector (self-employed, unpaid family workers, employees of microenterprises and domestic servants) increased 
Table 2 Latin American countries in the three informality groups ranked by social insurance coverage: circa 2004

\begin{tabular}{lll}
\hline $\begin{array}{l}\text { Importance of informal labour } \\
\text { force in countries }\end{array}$ & $\begin{array}{l}\text { Coverage of labour force by } \\
\text { pensions (\%) }\end{array}$ & $\begin{array}{l}\text { Coverage of total population by } \\
\text { health (\%) }\end{array}$ \\
\hline
\end{tabular}

\begin{tabular}{lcc}
\hline Low (average) & 45 & 57 \\
Chile & 57 & 72 \\
Costa Rica & 47 & 87 \\
Panama & 53 & 65 \\
Argentina & $24^{*}$ & 54 \\
Uruguay & 59 & $6^{+}$ \\
Brazil & 45 & $-{ }^{*}$ \\
Mexico & 28 & 45 \\
Medium (average) & 19 & 29 \\
Colombia & 22 & 53 \\
Venezuela & 21 & 38 \\
El Salvador & 20 & 16 \\
Dominican Republic & 14 & 7 \\
High (average) & 15 & 17 \\
Guatemala & 20 & 17 \\
Ecuador & 19 & 17 \\
Honduras & 19 & 12 \\
Nicaragua & 16 & 8 \\
Peru & 15 & 26 \\
Bolivia & 10 & 26 \\
Paraguay & 9 & 12 \\
Ora
\end{tabular}

*Argentina's coverage fell sharply during the crisis but had improved by 2007. +Uruguay has a high coverage by collective mutual-aid institutions instead of social insurance. $\neq$ Brazil does not have health social insurance but a public system with very high coverage.

Based on Table 1 and Mesa-Lago (2008a); averages by author.

from an average of 42 per cent of the urban labour force in 1990 to 46 per cent circa 2005; whereas the rural informal sector (self-employed and unpaid family workers, in both agriculture and non-agriculture) stagnated from 54.7 per cent to 55 per cent because of growing urbanisation (based on ECLAC 2002, 2006a).

Table 1 shows the importance of total urban informal labour, its major type (urban self-employed) and total rural informal labour in 18 countries of the region (data on Cuba and Haiti are not available). Countries are divided into three groups (low, medium and high informality), and ranked within each group from the lowest to the highest level of informality. With few exceptions, the most developed countries have the lowest informality and the least developed the highest informality. In the low group, the urban informal sector averages 36 per cent, the urban selfemployed 19 per cent and informal rural labour
43 per cent, whereas the proportions in the middle group increase to 46 per cent, 35 per cent and 50 per cent, respectively, and in the high group proportions peak at 56 per cent, 36 per cent and 66 per cent, respectively.

Other urban informal types not disaggregated in the table for lack of systematic data on coverage are: domestic servants (averaging 6 per cent of the urban labour force, probably underestimated, and ranging from 2 per cent to 11 per cent - the latter being in Peru); employees of microenterprises (averaging 12 per cent of the urban employed labour force, also probably underestimated, and ranging from 7 per cent in Chile to 17 per cent in Bolivia); and unpaid family workers whose disaggregate proportion is unknown (based on ECLAC 2006b).

The rural informal sector lacks any disaggregation: Table 1 shows only self-employed and unpaid family 
workers combined. ECLAC does not provide disaggregated data on agricultural workers outside of large plantations, cooperative members and peasants.

Table 2 shows that, with few exceptions, coverage by pension and healthcare social insurance is highest in the group with low informality, declines in the medium group and is lowest in the high group: average pension coverage is 45 per cent in the low informality group, 19 per cent in the middle and 15 per cent in the high group, whereas healthcare coverage averages 57 per cent, 29 per cent and 17 per cent, respectively. Social insurance coverage is directly correlated with formal employment and inversely related with informality.

Reasons for the lower coverage in the informal sector are related to the social insurance system itself (legal exclusion or voluntary affiliation, heavy financial contributions, see next section) and to the characteristics of informal workers, albeit the sector is not homogenous. These include: unstable jobs and income; lower income relative to salaried formal employees; lack of an employer among the selfemployed (hence the absence of the employer's contribution and of an agent to deduct the worker's contribution); employers in microenterprises who easily evade affiliation; domestic servants that either collude with their employers to evade or fail to report the employer's violation of affiliation because of fear of dismissal; and difficulties to detect, enrol and collect from informal workers. Among agricultural workers outside of large plantations reasons are: dispersion, lack of employer, unstable work and very low income (particularly among peasants, squatters, shareholders, etc.). Informal workers may also have other more urgent, higher priorities than to join social insurance such as food, housing and their business. Last but not least, this article shows that the higher the proportion of informal workers in a country the more difficult it is to cover them, and labour flexibility has aggravated the lack of social insurance protection.

\section{Social insurance legal and actual coverage of} informal workers

This section focuses on the factors obstructing coverage of informal workers resulting from the social insurance system itself: legal treatment and financial conditions. We also relate those factors to actual coverage as reported by statistics from social insurance institutions, and give examples of policies implemented in some countries to compensate for the adverse system conditions (legal coverage from legislation, actual coverage from Mesa-Lago 2007, 2008a,b).

The urban self-employed average 29 per cent of the region's employed urban labour force; they have legal voluntary coverage on pensions in 14 countries; two countries exclude them and four grant obligatory coverage. On healthcare, 12 countries have voluntary affiliation, four exclude them or do not enforce legal mandatory affiliation, and only two have obligatory coverage (in addition, in Brazil and Cuba public universal systems cover these workers). Actual coverage ranges from 0.1-30 per cent for pensions and $0.2-15$ per cent for healthcare. $A$ great barrier to coverage is a contribution equal to the sum of the percentages paid by salaried workers and employers.

Conversely, domestic servants, which average 6 per cent of the employed urban labour force, have legal mandatory coverage in 12 countries for pensions and in 13 for healthcare but in three countries, this has little effect. Actual coverage ranges from 3-39 per cent for pensions and 3-31 per cent for healthcare, because many of these workers lack labour contracts; are unable to denounce evasion or conspire with the employer to evade.

Employees in microenterprises (an average of 12 per cent of the employed urban labour force) are often not covered as the law sets a minimum number of employees (5-10) for mandatory affiliation in enterprises. Coverage in microenterprises is between one-third and one-thirtieth of coverage in large enterprises. Even when coverage is mandatory, social insurance institutions neglect inspection to detect evasion by small enterprises because of the higher costs involved and concentrate on the easier and cheaper collection among larger enterprises.

Unpaid family members are normally excluded from coverage both in pension and healthcare programmes.

Only three countries provide full mandatory legal pension coverage to agricultural workers; the rest impose restrictions or have special regimes. These workers are legally excluded from health coverage in half of the countries; the other half covers mainly wage earners in large plantations and members of cooperatives in some countries. Self-employed 
Table 3 Share of types of informal workers, and their legal and statistical pension coverage in selected countries, circa 2004

\begin{tabular}{|c|c|c|c|}
\hline $\begin{array}{l}\text { Type of informal } \\
\text { workers/countries }\end{array}$ & $\begin{array}{l}\text { Type of informal/employed } \\
\text { labour force (\%) }\end{array}$ & Legal pension coverage & $\begin{array}{l}\text { \% of type of } \\
\text { informal covered }\end{array}$ \\
\hline \multicolumn{4}{|l|}{ Self-employed } \\
\hline Argentina & 17 & Obligatory & 30 \\
\hline Brazil & 23 & Obligatory & 23 \\
\hline Chile & 15 & Voluntary & 5 \\
\hline Colombia & 38 & Voluntary & 10 \\
\hline Costa Rica & 16 & Voluntary & 24 \\
\hline Mexico & 19 & Voluntary & 0.1 \\
\hline Nicaragua & 35 & Voluntary & 0.2 \\
\hline Paraguay & 30 & Voluntary & 0.2 \\
\hline Uruguay & 20 & Obligatory & 29 \\
\hline \multicolumn{4}{|l|}{ Domestic servants } \\
\hline Brazil & 9 & Obligatory & 27 \\
\hline Costa Rica & 5 & Obligatory & 39 \\
\hline Paraguay & 11 & Voluntary & 3 \\
\hline \multicolumn{4}{|l|}{ Agriculture/peasants" } \\
\hline Brazil & 54 & Special regime & 50 \\
\hline Chile & 23 & Obligatory & 41 \\
\hline Costa Rica & 10 & Obligatory salaried & 44 \\
\hline Ecuador & 48 & Special regime & 18 \\
\hline El Salvador & 21 & Large farms only & 6 \\
\hline Honduras & 44 & Obligatory $10+e m p l o y e e s$ & 2 \\
\hline Mexico & 18 & Special regime & 29 \\
\hline
\end{tabular}

*Percentage of the rural labour force that are self-employed and unpaid family workers in agriculture. Source Mesa-Lago (2008b); first column from Table 1; agriculture/peasants from ECLAC (2006).

peasants, sharecroppers, squatters etc. are normally excluded in both programmes. The proportion of the agricultural labour force that is insured for pensions oscillates between 4 per cent and 12 per cent in five countries; coverage of the rural population usually is one-third to one-sixth that of the urban population. Only three countries have introduced special social insurance pensions for rural workers or peasants covering 18 per cent of the rural labour force in Ecuador, 29 per cent in Mexico and 50 per cent in Brazil. Very few figures are available on health coverage of agricultural workers: 1.5 per cent in Ecuador (but 18 per cent of the rural population is covered by peasant insurance), 2 per cent in Honduras and 6 per cent in Mexico (where 29 per cent of the rural population is covered by peasant insurance).

In an attempt to explore the potential role of the system characteristics on coverage, Table 3 compares in selected countries, the stipulated legal mandatory or voluntary pensions coverage (the existence of special regimes for agricultural workers/peasants in some countries) for three types of informal worker (urban self-employed, domestic servants and agricultural workers/peasants) with their actual coverage. Table 3 adds the share of each of these groups of informal workers relative to the labour force.

Table 3 suggests that countries with mandatory insurance have considerably higher coverage than those with voluntary affiliation. For instance, among the self-employed, Argentina, Brazil and Uruguay have obligatory affiliation and cover 23-30 per cent of these workers, whereas those with voluntary affiliation only cover 0.1-10 per cent (Chile after 25 years of a structural pension reform only covers 5 per cent of the self-employed, mainly professionals with high incomes). An exception is Costa Rica that had voluntary affiliation until 2006 but covered 24 per 
cent of the self-employed for pensions because the state subsidised the low-income self-employed, matching their contribution with that of the employer they lacked. ${ }^{2}$ Similarly, among domestic servants, Brazil and Costa Rica have obligatory affiliation and reach 27-29 per cent coverage, whereas Paraguay with voluntary affiliation covers only 3 per cent. Among agricultural workers and peasants, countries with obligatory affiliation such as Chile and Costa Rica (for all salaried) cover 41-44 per cent, those with special regimes such as Brazil, Ecuador and Mexico cover 50 per cent, 18 per cent and 29 per cent, respectively, but El Salvador and Honduras with significant restrictions only cover 2-6 per cent. Nevertheless, the apparent positive relationship between mandatory coverage/special regimes and coverage may be also influenced by the proportion of informal workers in the labour force, thus countries with the highest coverage are those with the lowest informality and vice versa. Finally, the legal mandate for affiliation may not by itself improve coverage if the state fails to provide the needed subsidies to low-income informal workers. To reach more sound conclusions, more research is needed along with better statistics on informal workers and their coverage.

The healthcare system, rather than being neutral, can determine the degree of exclusion, for instance a segmented or highly segmented system without coordination and poor solidarity is typical of all countries with low coverage. In the least developed (high informality group) social insurance was introduced late, in some of these coverage has not yet expanded to all geographic areas (health facilities and personnel are concentrated in the capital city and urban areas), and several of them have large rural and indigenous populations which are difficult to incorporate. Furthermore, these countries endure a regressive distribution of health funds, allocating more to social insurance and private sectors than to the public sector that is legally in charge of the protection of the majority of the population, and the poor and low-income are burdened with out-ofpocket expenses. Conversely, countries with fairly unified and coordinated healthcare systems and solidarity have achieved higher coverage: social insurance in Costa Rica, Chile and Panama, and public systems in Brazil and Cuba.

In summary, the higher the proportion of informal workers in the labour force, the more difficult it is to cover them; countries that have legal obligatory affiliation have higher coverage than those with voluntary affiliation; fiscal subsidies to the lowincome self-employed and similar groups provide incentives for affiliation; special regimes for rural workers or peasants have better coverage than those with voluntary or restricted coverage; countries with relatively unified and/or coordinated healthcare systems have better coverage than those with segmented or highly segmented systems without coordination. More research is needed to separate internal factors (induced by the system) and external factors such as the size of informality and the characteristics of these workers, and other factors discussed in the next section.

\section{Inequalities in coverage, and protection of the poor and the elderly}

Social insurance coverage is also influenced by other factors, such as income, education, gender, degree of development, location and ethnicity. There is a positive relationship between coverage on the one hand and income, education, male gender, high degree of development, urban location and nonindigenous ethnicity on the other hand (see MesaLago 2008a).

The lower the income and education of the person, the lower his/her social insurance coverage and vice versa.

Gender inequalities in coverage are caused by external and system factors: in one-quarter of LatinAmerican countries, the female spouse is legally covered for maternity but not sickness or vice versa. Statistical coverage of women is lower than men, due to indirect insurance as a spouse dependent on the male insured. Direct access declines as women exit the labour force to raise children. Pension coverage of elderly women is much lower than among elderly men in most countries.

The best-covered geographic areas are the most developed, urbanised and wealthier, whereas the worst covered are the least developed, rural and poor. Only two countries have compensation funds to reduce geographic inequalities in healthcare.

Indigenous populations are largely excluded from coverage because they are poor or have low-income, work in the informal sector and/or live in rural areas. The three countries that have special programmes 
for rural and peasants have been able to cover part of them.

Poverty averaged 39.8 per cent of the population in 2005 and ranged from 47-75 per cent in nine countries (ECLAC 2006b). ${ }^{3}$ Only six, the most developed with the lowest poverty incidence (Argentina, Brazil, Chile, Costa Rica, Cuba and Uruguay), have targeted means-tested social assistance pensions but these do not cover all the poor. Thirteen countries lack social assistance pensions and they suffer the lowest coverage of contributory programmes and the highest poverty incidence. Bolivia with 64 per cent poor has a nontargeted universal flat pension granted to part of those who get a contributory pension. And yet social assistance pensions have significantly reduced poverty. International financial organisations have given priority in the last decade to the mandatory private savings 'pillar' and seriously neglected the poverty-prevention public 'pillar'; a group of Bank officials have now recommended a reversal in such priorities (Gill et al. 2005). A Chilean legal draft currently under discussion in the parliament creates a universal basic pension for the population in the lowest 60 per cent of income. Estimates of costs of supplementary means-tested schemes indicate that they are financially viable and would reduce poverty by about 18 percentage points (ECLAC 2006a).

Coverage of the elderly population (age 65 and above) by pensions is worst in the least developed countries (5-20 per cent in Bolivia, Ecuador, El Salvador, Guatemala, Nicaragua and Paraguay) and best in the most developed countries (62-87 per cent in Argentina, Brazil, Chile, Costa Rica and Uruguay). In three of the latter, coverage has declined through time: Argentina, Chile (in the contributory programme but compensated by social assistance pensions) and Uruguay (Rofman 2005; Mesa-Lago 2008a). Such evidence is contrary to the World Bank prediction that poverty among old people will decrease over time in the region (Gill et al. 2005). Actually the noted decline in coverage of the active labour force in most countries is resulting in decreasing protection of the elderly cohort of the population that is rapidly growing in the region. Social insurance pensioners in all countries (except Haiti) are entitled to health coverage, but in Nicaragua they receive a mini package of benefits which is considerably lower than for active insured workers.

\section{Conclusions and lessons from Latin America for other developing countries 5.1 Factors that influence coverage}

Low and stagnant or declining social insurance coverage in the region is shaped by: (1) the transformation of the labour market; (2) the lack of adaptation of social insurance to such change in most countries; (3) the failure of most systems and reforms to design programmes capable of expanding coverage, largely due to the exclusion of informalrural workers and the poor, and (4) external factors.

The higher the proportional size of informal-rural groups in the labour force, the more difficult they are to cover, but some countries have implemented successful inclusion policies, mainly the most developed.

Social insurance pension programmes and reforms (particularly but not exclusively private systems) were originally designed for urban formal workers, with stable jobs, medium-high salary and high density of contribution (most of them male), but the majority of the labour force in the region is informal and/or agricultural, with unstable employment, low wages and poor density of contribution (especially among women), hence coverage is very difficult to extend.

Segmented healthcare systems without coordination and poor solidarity are typical of all countries with low coverage; in the least developed, social insurance was introduced late, some have not expanded coverage to all geographic areas, and several have large rural and indigenous populations that are difficult to incorporate.

External factors in addition to labour-market transformation are: underdevelopment, elevated poverty incidence, gender inequality, cultural and ethnic barriers, a large rural population, poorly developed regions, lack of government commitment, and scarce or improperly assigned fiscal resources.

\subsection{Policies}

\section{Expansion of coverage}

The idea that development will eventually expand the formal sector and thus extend coverage is contradicted by factual evidence in Latin America over the last 25 years. Social insurance, therefore, must adapt to the transformation of the labour market, expanding coverage to informal and rural workers and peasants, the poor and the elderly. 


\section{Incorporation of difficult groups}

Countries that have legal obligatory affiliation have higher coverage than those with voluntary affiliation but legal inclusion by itself is insufficient: fiscal subsidies to the low-income self-employed and similar groups provide incentives for affiliation (Costa Rica); special regimes for rural workers or peasants get better coverage than those with voluntary or restricted coverage but with diverse results due to diverse government commitment and financial support (better in Brazil than Mexico and Ecuador).

\section{Reduction of inequalities require}

Integration or good coordination between the public and social insurance sectors in segmented health systems to eliminate overlapping, save resources, and extend coverage to those excluded; granting fiscal subsidies to poor or low-income groups (as in Chile) or to guarantee the basic package of health benefits

\section{Notes}

1 Structural reforms passed in Ecuador and Nicaragua failed to be implemented due to annulment or declaration of unconstitutionality.

2 Obligatory affiliation began for pensions in 2006 and should have increased coverage. Similar state subsidies for low-income self-employed in healthcare social insurance increased coverage to 45 per cent of that group.

\section{References}

Economic Commission for Latin America and the Caribbean (ECLAC) (2006a) La Protección Social de Cara al Futuro: Acceso, Financiamiento y Solidaridad, Montevideo: Trigésimo Período de Sesiones

Economic Commission for Latin America and the Caribbean (ECLAC) (2002, 2006b, 2007) Social Panorama of Latin America 2001-2002, 2006, 2007, Santiago de Chile

Gill, Indermit, Packard, Truman and Yermo, Juan (2005) Keeping the Promise of Social Security in Latin America, Washington DC: Stanford University Press and World Bank

Mesa-Lago, Carmelo (2008a) Reassembling Social Security: Pension and Healthcare Reforms and their Effects in Latin America, Oxford: Oxford University Press in the entire system regardless of age, gender and risk (as in Colombia and Argentina); making financing proportional to income or progressive as income increases; elimination of fiscal subsidies awarded to non-poor (free riders); extension of legal comprehensive health coverage to the spouse of the insured, granting optional insurance to housewives and bonuses to women that exit the labour force to raise their children; and priority to cover indigenous peoples targeting the geographic areas where they live.

\section{Poverty and the elderly}

Priority should be given to the poverty prevention pillar through social assistance pensions targeted on the poor, which are less costly than universal nontargeted pensions. Increasing coverage of the active labour force will improve coverage of the elderly in the long run.

3 ECLAC (2007) preliminary estimates indicate an astonishing cut of ten percentage points in poverty incidence between 2005 (39.8 per cent) and 2006 (29.8 per cent) largely influenced by significant cuts in the three countries with the largest populations: Brazil, Mexico and Argentina.

Mesa-Lago, Carmelo (2008b), 'Social Insurance (Pensions and Health), Labour Markets and Coverage in Latin America', in Katja Hujo (ed.), Financing Social Policy, Geneva: UNRISD and Basingstoke: Palgrave McMillan.

Mesa-Lago, Carmelo (2007) 'The Extension of Healthcare Coverage and Protection in Relation with the Labour Force: Problems and Policies in Latin America', International Social Security Review 60.1: 3-36

Rofman, Rafael (2005) Social Security Coverage in Latin America, Social Protection Discussion Paper Series 0523, Washington DC: World Bank

Tokman, Víctor E. (2007) 'De las Reformas del Consenso a las Reformas para el Desempleo Estable', Seminario Cohesión y Protección Social en América Latina, Barcelona: CIDOB 